\title{
Automatic Street Light Control System With and Without Internet of things
}

\author{
Polamreddy Girija ${ }^{1}$, palvoi Kishore Babu ${ }^{2}$, Gudumcherla Salma $^{3}$, B Venkatesh Naik $^{4}$ \\ ${ }^{1}$ Gitam, India, 3210416136@ gitam.in \\ ${ }^{2}$ Gitam, Country, 3210416134@gitam.in \\ ${ }^{3}$ Gitam, India, 3210416111@gitam.in \\ ${ }^{4}$ Gitam, India, vbanakar@gitam.edu
}

\begin{abstract}
Generation of electric power generation, transmission and distribution are main parts of electrical network along with this utilization of electrical power plays an important role for completion of electric power cycle from generation of power to its destination. Electrical power is utilizing in many applications, among these applications street lights are the main loads for consumption of electrical power. But control mechanism for switch on and switch of the street light should be punctual. If street lights are not get operated properly then there will be huge wastage of electrical energy will occur and it may lead to greater loss of distributed companies. Hence proper control mechanism for the street light operation is mandatory. There are so many mechanisms are existed for the controlling of street lights. In this paper an Internet of things based module node MCU is prepared to control the multiple numbers of street lights which reduces the manpower for its operation. Also architecture has built without Internet of things, that is by using 555 timer which is used to operate the street light without any internet. The comparison based on cost, working, and life span feasibility has done. This performance comparison has carried through hardware and coding has done in Arduino IDE..
\end{abstract}

Key words: IoT: Internet of things, 555 timer, light dependent resistor, Aurduino uno

\section{INTRODUCTION}

Many technologies have emerged to automatic control of electrical devices. Enormous research has done in the field of electrical technology to reduce the electrical energy wastage. We know that if we save just one unit if electrical energy that will be equal to ten units of generating electrical energy. Ultimately equal importance has to give for saving electrical energy along with its generation. As street lights are main load for the consumption of electrical energy, their operation and control plays significant role. It is necessary to minimize the electrical energy wastage by incorporating the automatic control of street lights. A technology used STM32 for the lighting control system particularly applicable for the smart city lighting system, an internet of things based system has designed to control the street lights. Control and feasibility of the system is done with the help of Internet of things by using STM32 [1]. Based on the cloud and environmental conditions the intensity of the light on the lamps will decide their operation, this methodology is implemented based on locations where wide variations in environmental conditions and rapid changes in the cloud moment occur. Technology here used is cloud computing, web of things and internet net of things [2]. A control circuit has designed by using the power electronics devices and the voltage across the lamb can be controlled by using TRIAC based on the sum rays falling on the street lights during sunrise and the sunset. These things of sunrays, sunrise and sunset information can be collected from the internet and architecture has designed by combining internet of things and power electronics control devices [3]. To reduce the energy wastage in urban areas the technology which utilized the PLC and the internet of things to switch off and switch on the street lights based on the sunlight light intensity on the LED bulb is used. This technique is mainly used in the urban areas where most of the street lights are working through the night [4]. In order to minimize usage of the city electric power a model is developed, which utilizes the natural source of energy that is solar energy to charge the battery which is placed on the street light pole. The street light utilizes the energy stored in the battery to glow during the night and if the energy stored in the battery over than the street light will glow by taking the energy from the actual supply [5]. With the help of emerging technologies the street lights operation has upgraded for installed power at particular locality, estimating the energy waste and finding the amount of energy up gradation the operating equipments to that the overall operation and the efficiency of the system have improved [6]. Smart cities have incorporated the different layer of protocols for the operation of the street lights as well as the public awareness for the saving of the electrical energy. The methodology uses the Internet of things, wifi module and radio frequency signals for 
its operation [7]. Along with the automatic control of the street lights the automatic traffic control signal also designed which utilizes the vehicle density capture $b$ the camera. The automatic street light system operates with help of the light dependent resistor, based on the amount of light falling on light emitting diode, the light emitting diode may be in ON state or in OFF state or it may be dim [8]. With the help of the MQTT which is working on the internet of things the operation of the street light automatically has enhanced [9]. Along with an automatic control of the street, a facility has given for the person those who are in danger at that street can press an emergency button which will connects call or enables the person to get communication with the nearby police station [10].

\section{PRAPOSED MODEL}

In this paper we have designed two modules which will work by using with internet of things and also without internet of things with the help of arduino uno board and 555 timer respectively, which in turn uses the light dependent resistor. The usage of arduino uno board helps in controlling the multiple numbers of street lights. The implementation of 555 timer also controls the street lights very efficiently. This has been performed in the laboratory and executed.

\subsection{Timer}

It is an electronic integrated chip used widely in the field of electronics. It is used to generate the constant pulses at particular time instants time instants. It will works in two modes constable mode and a stable mode. In monostable mode of operation the times generates its duty cycle based on the external components like resistor or capacitor. Whereas the in astable mode of operation both the number of cycles per second as well as the duty cycle depends on the external components like resistor or capacitor. In the project we have used 555 timer to generate the continues pulses in order to operate the street lights automatically. The pin diagram of 555 timer is as shown in figure 1.

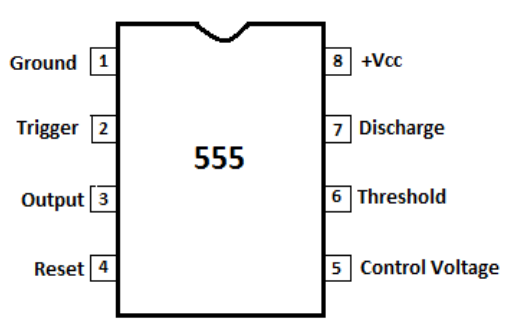

Figure 1: pin diagram of 555 timer

\subsection{Arduino Uno}

Arduino is a hardware kit which is used to interface between the software and the equipment to which we need to control. It is based on the microcontroller having 14 input and the output pins. The code which is used to control the required parameter should dump here and I performance the desired. ATMEL 328 kit is used here in which the code has dumped to control the automatic street light. Figure 2 shows the layout of the kit. A 7 volt battery is used to operate the kit. The performance of the kit purely depends on the micro controller used in it.

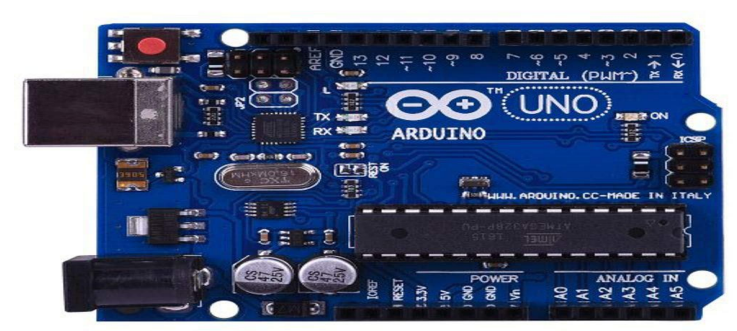

Figure 2: Arduino uno kit

\subsection{IR Sensor}

An important component to get the information of the light incandescing on the light dependent resistor is the infrared sensor. It senses the light in the form of the infrared radiation and gives signal to the further part of the kit. It can be used in any condition irrespective of the environmental stats. Figure 3 below shows the structure of the infrared sensor.

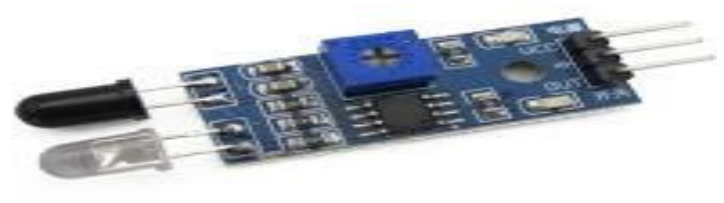

Figure 3: infrared sensor

\subsection{Light Dependent Resistor}

As the name itself indicates the value the resistance depends on the amount light intensity falling on this. This property of the LDR is used in many electrical applications. The main working principle of this device is like when the amount of lights intensity falling on this devise is increases than its resistance will increase and when the amount of light falling on it decreases than its resistance increases in terms of mega ohms. This property of the light dependent resistor is used to operate the street lights automatically. Figure 4 gives shows the neat sketch of the light dependent resistor. 


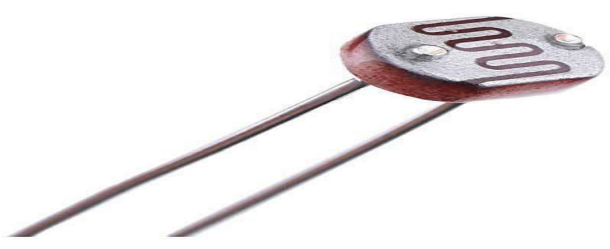

Figure 4: light dependent resistor

\subsection{Control Mechanism Without Internet of Things}

Figure 5 in the above circuit gives clear picture about the automatic control of the light emitting diode that is the light emitting diode operates based on the light intensity on the light dependent resistor. A five volt battery is used to on or switch off the LED. A ten kilo ohm variable resistor s used to control or set the frequency or to limit the timer in case of any excess flow of the current. The pin number six and four of the timer has short circuited and the connoted to the positive terminal of the supply voltage. The light dependent resistor is connected between the pin number 8 and 2 whose resistance varies depending on the light intensity on it. The output terminal of the timer that is pin number 3 is connected to the one end of the LED and another end connected to the negative terminal of the supply voltage. During night time or when the darkness is there on the light dependent resistor its value reaches to maximum value. Under this condition the trigger pin of the timer that is the pin number 2 gets voltage the one third of the supply voltage so the out pin of the timer under this condition is low and the LED will glow. Similarly in the morning time the light intensity on the light dependent resistor is more and hence its resistance is less, during this condition the trigger pin 2 gets voltage more than the one third of the supply voltage then the output of the timer falls to low and the LED will get off.

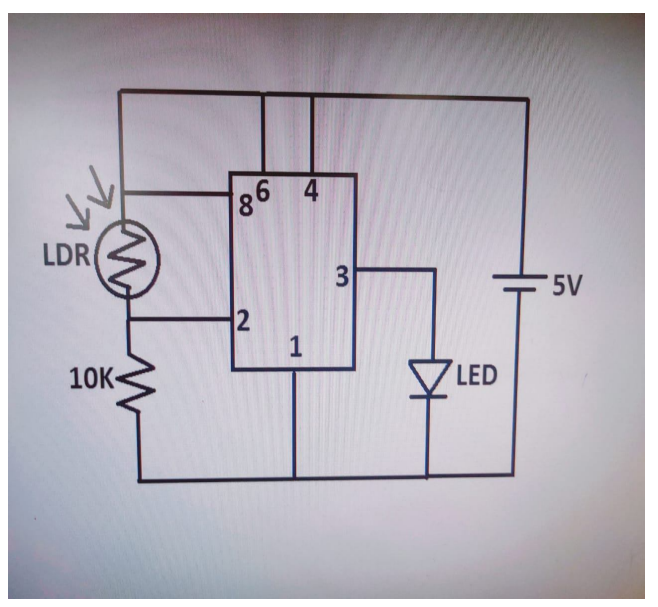

Figure 5: Implementation of 555 timer to control the street light

\subsection{Control Mechanism with Internet of Things}

Figure 6 gives architecture of the system which is used to control the street lights automatically with internet of things. Here we have used ATMEGA328 an Arduino board which works on the microcontroller. In the figure 6 we have shown only required pins. LED is connected between pin numbers D3and infrared sensor. The sensor is connected to the $5 \mathrm{~V}$ supply and the light dependent resistor

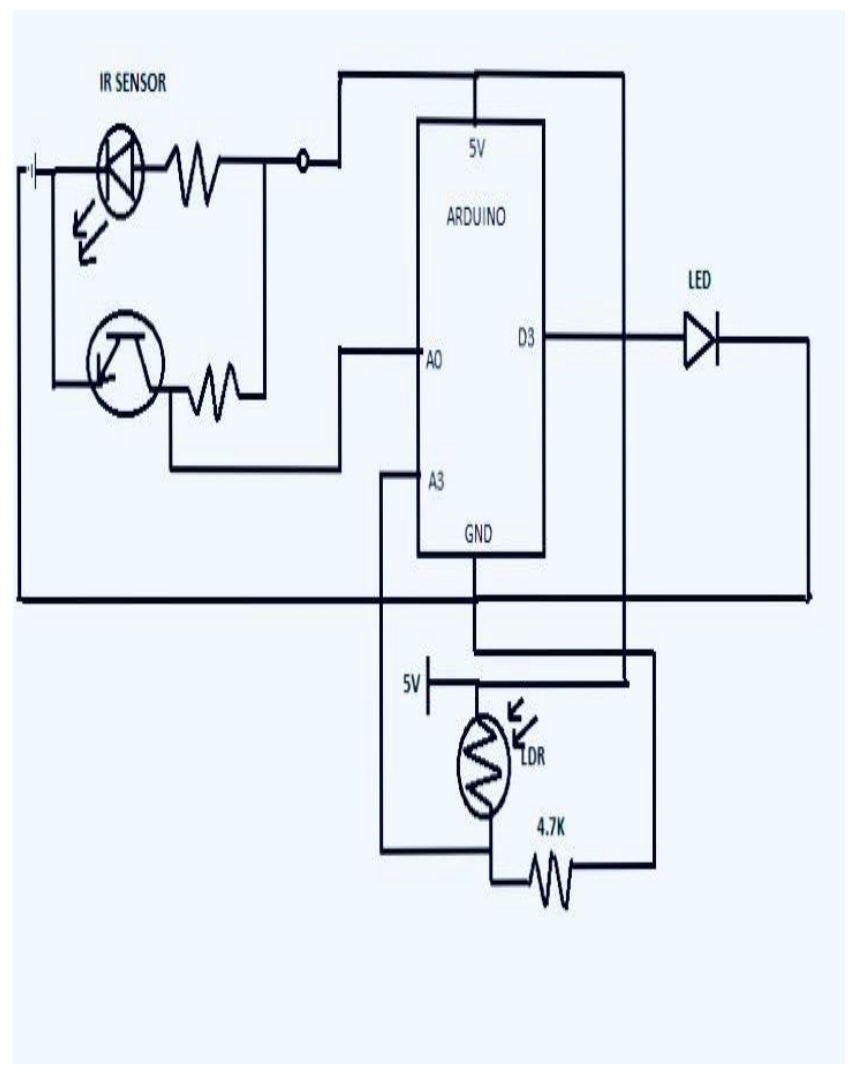

Figure 6: Architecture to control street lights with IoT

Figure7 gives flowchart of the code dumped into the system and the street lights will operate based on this code. we have defined the sensor pin to A0, sensor value as zero and LED connected to pin number D3. Output of sensor value will defined as 9600 band. The sensor will sense the value of light intensity from $\mathrm{A} 0$ and it will be stored. If the stored value is less than the 100 than the LED will glow otherwise it won't glow. The sensor senses the light based on the working of light dependent resistor 


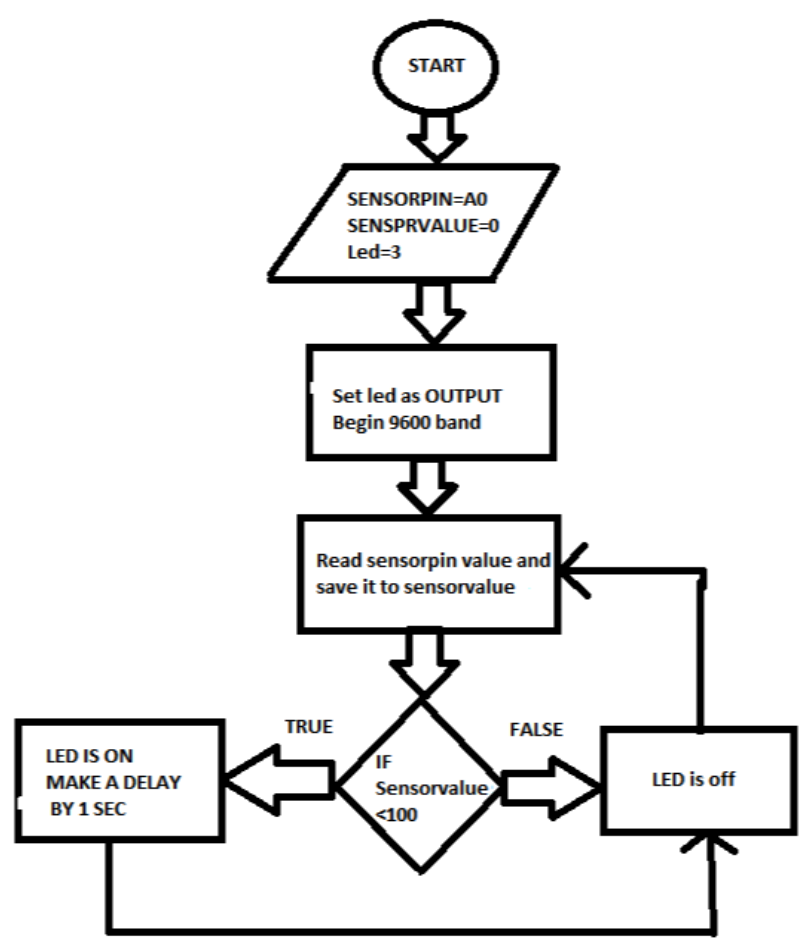

Figure 7: flow chart of the code

\section{RESULT AND CONCLUSION}

The conduction of the setup has done in laboratory and the results were obtained. Figure 8 and 9 shows the LED is off when the light is falling on it and the LED is glowing when it is in the darkness respectively. The electrical power saving is the major challenge in the current universe. So we have to adopt new technologies to save the electrical power. Major loads for the power plants are street lights. Regulating, operating and control of the street lights is mandatory to save electrical power hence these methods are very useful. Among these two the IoT based project gives efficient results and we can use this control many street lights but cost is quite high compare to 555 timer. The intensity on the LDR and LED at different time intervals are as shown in table 1.

Table 1: Values of light intensity on LDR and LED measured at different time intervals

\begin{tabular}{|c|c|c|c|}
\hline Serial $\mathbf{N}_{\mathbf{0}}$ & Time & $\begin{array}{c}\text { Light Intensity of } \\
\text { LDR ( } \mathbf{( x )}\end{array}$ & $\begin{array}{c}\text { Light Intensity of } \\
\text { LED (cd) }\end{array}$ \\
\hline 1 & $12: 02$ & 38 & 182 \\
\hline 2 & $12: 10$ & 28 & 157 \\
\hline 3 & $12: 20$ & 9 & 212 \\
\hline 4 & $12: 24$ & 8 & 200 \\
\hline 5 & $12: 26$ & 14 & 189 \\
\hline 6 & $12: 30$ & 20 & 186 \\
\hline
\end{tabular}

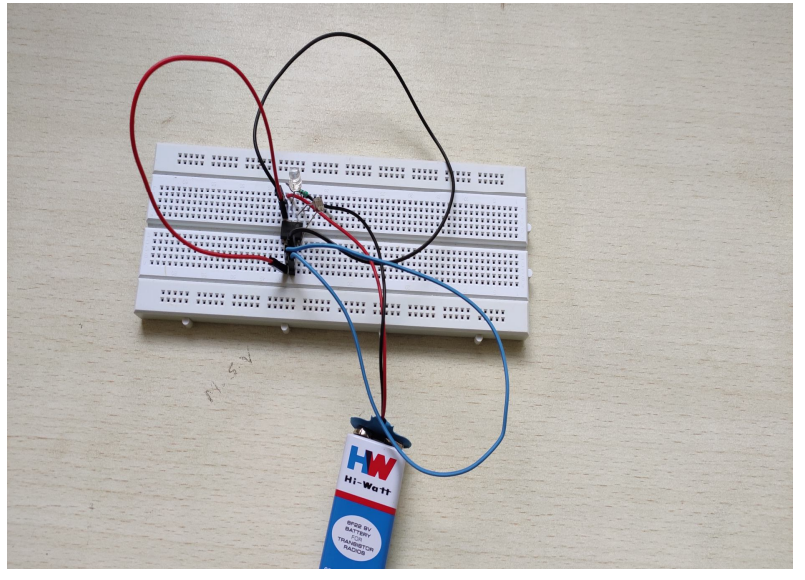

Figure 8: LED off during light falls on LDR

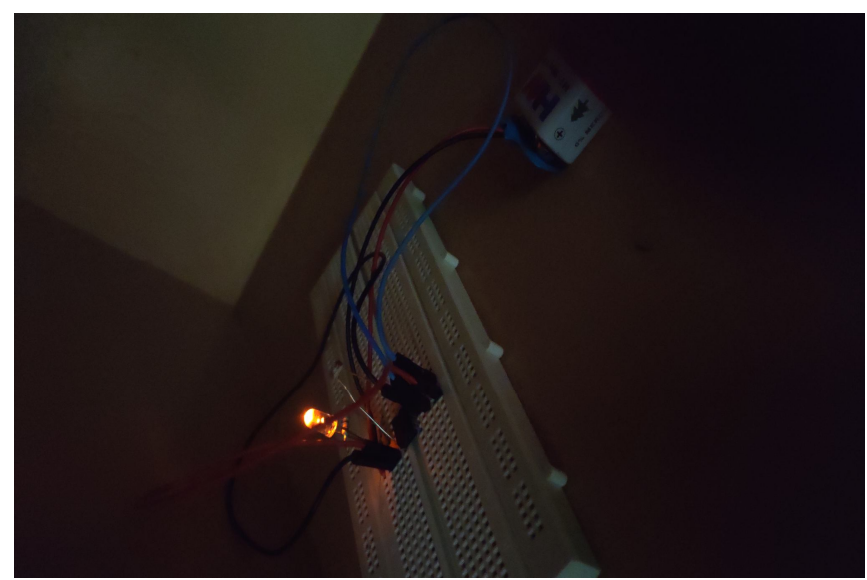

Figure 9: LED is ON during darkness

Figure 10 shows that the LED is ON when the light dependent resistor is surrounded by full of darkness. Similarly the figure 11 shows that when the light intensity falls on light dependent resistor the LED will be off.

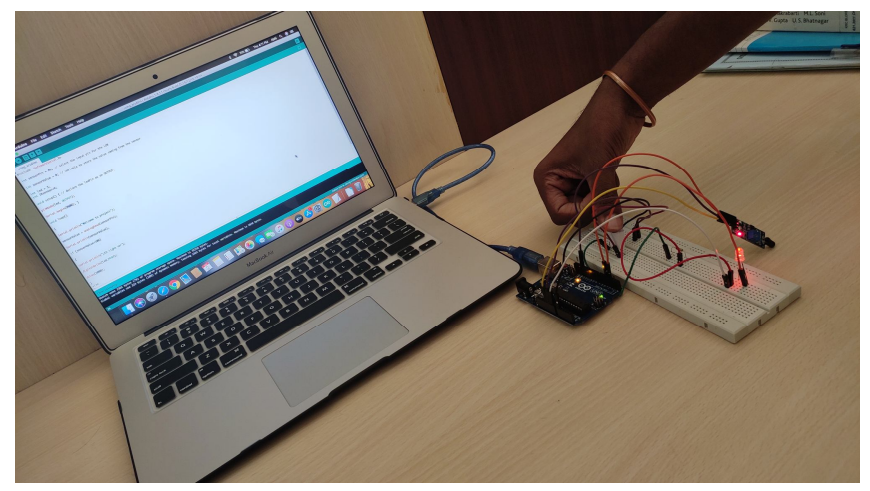

Figure 10: LED glows when light dependent resistor surrounded by darkness 


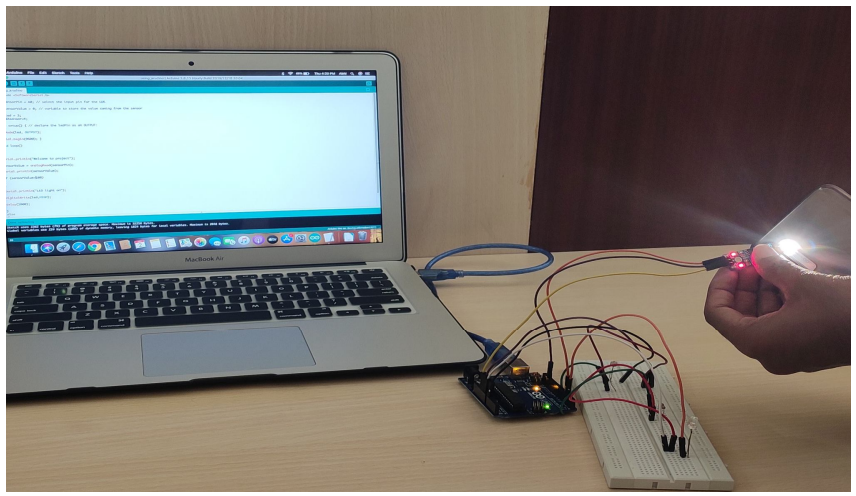

Figure11: LED is off when light intensity falls on light dependent resistor

\section{ACKNOWLEDGEMENT}

We are grateful to our director Dr. Dinesh seth who guided and encouraged us to do this project since long back. We also give our sincere thanks to our head of the department Temkar N Ruckmongathan who has motivated to us regarding our project. Also we will give our thanks to Mr. Umesh junior engineer working in GESCOM who gave us much information.

\section{REFERENCES}

1. Shichao chen, Gang Xiong, Jia Xu, Hungashuang Han, Fie Yue Wang, Kun Wang, "The Smart Street Lighting System Based on NB-IoT" in 2018 IEEE conference.

2. Mahamut Durgun, Levent Gokrem, "Cloud Based Adjustable and LED Pattern Controlled System" in 2019 IEEE. https://doi.org/10.1109/AIACT.2019.8847902

3. Omkar Rudrawar, Sidhharth Daga, Janak Raj Chadha, P S Kulkarni, "Smart street lighting System With Light Intensity Control Using Power Electronics" in 2019 IEEE. https://doi.org/10.1109/ICSESP.2018.8376692

4. Landcheng Zhao, QUIONG Gao, Ran Wang, Nan Fang, Zhuqi jin, Neng Wan, Lianming Xu, "Intelligent Street Light System Based onNB-IOT and Energy Saving Algorith" in IEEE.

5. Basri Kul, "Iot GSM Based High EfficiencyLED Street Light Control System" 10Proc.XXVIInternational Scintific ComferenceElectronics -ET2017, September 13-15, 2017,Sozopol, Bulgaria

6. Ashish Phandaripande, Sajith Payyadakath, "Energy Data Service With Connected Street Lighting" in 2019 IEEE 5th World Forum on Internet of Things.

7. Andras Szlai, Andras Timar, "SmartSSl:application of IoT/CPS Desgin Platform in LED sterrt lighting luminaries" in 2016 IEEE.
https://doi.org/10.1109/LUMENV.2016.7745518

8. Mohd.Saifuzzaman, Nazmunn Nessa moon, Fernaz Narin Nur, "IoT Based Street Lighting and Traffic Management system" in 2017 IEEE Region 10 Humanitarian technology Conference. https://doi.org/10.1109/R10-HTC.2017.8288921

9. Karthik S Murthy, Parul Herur, Aditya B R, Harshita Lokesh, "IoT Based Light Intensity Controller" in ICIRCA 2018. https://doi.org/10.1109/ICIRCA.2018.8597416

10. B.Abhinaya, S.Gurupriya, M.Pooja, "IoT Based Smart and Adaptive Lighting in Street Lighting" in 2017 IEEE. https://doi.org/10.1109/ICCCT2.2017.7972267

11. Md M Pasha, G V S Rao, "Sparse Non-stationary Thermal Wave Imaging for GFRP" in International Journal of Emerging Trends in Engineering Research.

12. Hennadii Khudov, Irina Khizhnyak , Fedor Zots , Galina Misiyuk, Oleksii Serdiuk, "The Bayes Rule of Decision Making in Joint Optimization of Search and Detection of Objects in Technical Systems" in International Journal of Emerging Trends in Engineering Research.

13. M Siva Kumar, Fazal Noorbasha, Syed Inthiyaz, M. Jameela , A. Sandhya , Md. Imran , Sanath Kumar Tulasi, "Low Power Carry Look-Ahead Adder using Transmission Gate Multiplexer" in International Journal of Emerging Trends in Engineering Research. 